\title{
Socioeconomic and demographic factors are associated with dietary patterns in a cohort of young Brazilian adults
}

Soraia Pinheiro Machado Arruda', Antônio Augusto Moura da Silva², Gilberto Kac ${ }^{3}$, Marcelo Zubaran Goldani ${ }^{4}$, Heloisa Bettiol ${ }^{5}$ and Marco Antônio Barbieri ${ }^{*^{*}}$

\begin{abstract}
Background: The aim of the present study was to identify the main dietary patterns among young adults and to investigate the association of socioeconomic and demographic factors, and social mobility with dietary patterns.

Methods: Data from the fourth follow-up of the 1978/79 Ribeirão Preto birth cohort study, Brazil, were used. A total of 2,061 young adults, whose mothers gave sociodemographic information at birth in 1978-79, provided sociodemographic and dietary data through a validated food frequency questionnaire in 2002-2004, when they were aged 23-25 years. Those whose caloric intake was outside of the \pm 3 standard deviation range were excluded, leaving 2,034 individuals. The dietary patterns were identified by principal component analysis followed by varimax orthogonal rotation. Poisson regression with robust estimation of variance was used to derive prevalence ratios (PR).

Results: Four dietary patterns were identified: healthy, traditional Brazilian, energy-dense and bar. In the adjusted analysis, individuals with higher schooling ( $\geq 12$ years) in adult life ( $P R=1.51,95 \% \mathrm{Cl}: 1.07-2.14)$ showed greater adherence whilst men ( $P R=0.79,95 \% \mathrm{Cl}: 0.68-0.93)$ had lower adherence to the healthy pattern. The highest adherence to the traditional Brazilian pattern was found for men ( $\mathrm{PR}=2.39,95 \% \mathrm{Cl}: 2.04-2.80)$, mullatos ( $\mathrm{PR}=1.41,95 \% \mathrm{Cl}$ : 1.21-1.64), households with $\geq 2$ members, and for those with children ( $P R=1.28,95 \%$ Cl: 1.07-1.55) while individuals with higher schooling in adulthood ( $\geq 12$ years) ( $P R=0.47,95 \% \mathrm{Cl}: 0.34-0.65$ ), higher family income in adulthood ( $\geq 20 \mathrm{MW}$ ) $(\mathrm{PR}=0.57,95 \%$ Cl: $0.33-0.99)$ and higher family income at birth ( $\geq 6.1 \mathrm{MW}$ ) showed lower adherence. The bar pattern was positively associated with male sex ( $P R=2.96,95 \% \mathrm{Cl}: 2.47-3.55)$ and low schooling ( $\leq 8$ years). The energy-dense pattern was not associated with any of the variables investigated. Social mobility was associated with the traditional Brazilian pattern. Men and women who were not poor at birth and remained so in adulthood showed lower adherence to this pattern ( $P R=0.70,95 \%$ Cl: $0.53-0.94$ for men and PR $=0.40,95 \%$ Cl: $0.20-0.80$ for women).
\end{abstract}

Conclusions: Four different dietary patterns were identified among young adults. Socioeconomic and demographic factors, and social mobility were associated with food choices.

Keywords: Dietary patterns, Socioeconomic factors, Young adults, Social mobility, Cohort study

\footnotetext{
* Correspondence: mabarbieri@fmrp.usp.br

${ }^{5}$ Department of Puericulture and Pediatrics, Faculty of Medicine de Ribeirão Preto, University of São Paulo, Av. Bandeirantes, 3900, Monte Alegre, Ribeirão Preto, São Paulo 14.049-900, Brazil

Full list of author information is available at the end of the article
} 


\section{Background}

Extensive epidemiological studies have been conducted in order to identify factors that might attenuate the burden of non-communicable diseases. Diet is one of the main modifiable risk factors $[1,2]$.

However, the approach traditionally used by most studies within the field of nutritional epidemiology is based on the investigation of the specific effect of individual nutrients or foods on health. The variety of foods in a diet results in a complex combination of chemical compounds that may be antagonistic and that may compete with each other or may alter the bioavailability of other chemical compounds or nutrients. Thus, examining the individual effect of foods and nutrients on the risk of disease has serious limitations [3-6].

The analysis of food consumption based on dietary patterns helps disease prevention and treatment, and thus represents a fundamental tool for programs of nutritional intervention $[7,8]$. Some statistical techniques are employed for the identification of dietary patterns, in an attempt to examine the effect of overall diet on disease risk. The number of dietary variables is reduced and a combination of nutrients and foods that are easy to analyze is then used $[4,9,10]$.

Although dietary patterns are not stable among different populations, many studies have identified similar patterns. The "western" pattern, that usually consists of red meat, whole dairy products, processed foods and refined grains, and the "prudent or healthy" pattern of fruits, vegetables, whole grains and fish, are among those commonly identified [9].

Demographic, socioeconomic, biological and nutritional factors have been associated with dietary patterns $[5,11]$. For example, some studies have shown that women follow healthier dietary patterns than men $[9,12]$. Similarly, the association of healthy dietary patterns with high income and educational level has been well established [11]. However, it is still unclear to what extent this association is related to current or early socioeconomic characteristics, especially during childhood, when dietary preferences are partially established [13].

Most of the studies investigating the dietary patterns of populations have been conducted in developed countries. It was only in the last decade that studies started to be conducted in developing countries such as Brazil [3,5,6,11,14-18]. Although most of the Brazilian studies have investigated adult populations, specific studies on young adults are scarce $[16,18]$. It is not known whether the same dietary patterns would be found in different regions of middle-income countries and if the associations of socioeconomic, demographic conditions and social mobility with these dietary patterns would be similar.

The objective of the present study was to identify the dietary patterns of young Brazilian adults and to investigate the association of socioeconomic and demographic factors, and social mobility with these patterns in a birth cohort from Ribeirão Preto, São Paulo, Brazil. This knowledge can guide planning and implementation of strategies to promote healthy eating practices aimed at preventing noncommunicable diseases in later life.

\section{Methods}

The study was based on the Ribeirão Preto, birth cohort study, started in 1978/79, involving children born in hospitals to mothers residing in the municipality. The current study used data collected in the first and fourth phase of the investigation, the latter covering the years from 2002 to 2004 [19]. Ribeirão Preto is the eighth most populous municipality in the State of São Paulo, in the Southeast region of Brazil. The population was 318,496 inhabitants in 1979 , with $96.8 \%$ of them residing in the urban region. In 2003 , the population was 534,828 inhabitants.

\section{Study population}

In the study period, there were 9,396 live births in the maternity hospitals, corresponding to $98 \%$ of all liveborns in Ribeirão Preto, the rest being home births. Of those that were born in the maternity hospitals, we were not able to contact 235 (2.5) due to early discharge. Of the invited, 94 $(1.0 \%)$ refused to participate in the study, leaving 9,067 individuals for inclusion. Then we excluded children whose families did not reside in the municipality $(2,094)$ and twins (146), being the baseline sample at birth composed of 6,827 singletons.

In 2002/04 in the $4^{\text {th }}$ follow-up, when the study members were aged $23-25$ years, 343 subjects have died before completing 20 years of age leaving 6,484 individuals. Attempts were then made to invite for medical examination a non-random sample based on one-in-three of this group. The first of every three names was selected from a list sorted by birth date in each geographic region and if unavailable, the next name down was selected. Based on the records of the Unified Health System and of private health care plans and on the contacts made in the 2nd and 3rd phase of the study, we were not able to locate 819 , leaving 5,665 subjects. The losses due to refusal to participate in the study (209 cases), to death after 20 years of age (34 cases), imprisonment (31 cases) or failure to attend the interview (431 cases) corresponded to a total of 705 individuals. Losses were replaced using the same sampling frame, resulting in 2,063 young adults aged 23 to 25 years, corresponding to $31.8 \%$ of the 6,484 eligible subjects, participating in the 4th phase of the study of the Ribeirão Preto cohort [19]. Two subjects were excluded because they did not fill out the food frequency questionnaire and 27 because they reported energy intake outside the range $\pm 3 \mathrm{SD}$, leaving 2,034 cases for analysis. 
The study was approved by the Research Ethics Committee of the Faculty of Medicine of Ribeirão Preto, University of São Paulo, and all subjects gave written informed consent to participate.

\section{Explanatory variables}

At the time of birth, the mothers responded to a standardized, pre-coded and pre-tested questionnaire applied by trained interviewers [20]. The data considered for analysis in the present study were family income and maternal schooling. In young adulthood, the participants answered a questionnaire containing socioeconomic and demographic data. The variables considered were: sex, skin color, marital status, presence of children in the household, number of people in the household, family income in adult life, and schooling. Schooling was recorded as completed years of study. Monthly family income consisted of the sum of the income of family members residing in the household, converted to multiples of the Brazilian minimum wages (MW) for each period (corresponding to US\$ 84.0 in 1978 and US\$ 89.8 in 2003). Per capita family income was also calculated as the total family income divided by the number of family members. The information about family income obtained at the two time points was used to create the variable social mobility, which expresses life-long changes in family income. The family income of the first and fourth phase of the study was categorized into tertiles, with the first tertile being labeled poor, and the second and third tertiles not poor. Thus, social mobility was classified into four categories according to income tertiles at birth and adulthood: poor - poor, poor - not poor (ascending mobility), not poor - poor (descending mobility), and not poor - not poor.

\section{Dietary assessment}

Dietary data were obtained by applying a Food Frequency Questionnaire (FFQ) validated for the Japanese-Brazilian community of São Paulo [21], with foods of Japanese origin being excluded. The reproducibility of the FFQ was assessed by repeated administration at one-month interval. The relative validity was evaluated by comparison with dietary intake obtained from four three-day weighed dietary records (DR), covering the same 12-month period assessed by the FFQ. The authors [21] conclude that this FFQ is reproducible and can be used to classify persons according to their nutrient intake over a one-year period.

The adapted FFQ contained 75 food items, the respective options of consumption frequency in the last year and the size of the mean reference portion so that the individual could estimate whether his regular consumed portion was small (smaller than the presented one), medium (equal to the presented one) or large (larger than the presented one). The questionnaire was applied, by a nutritionist, only to young adults at the 4th follow-up in 2002-
2004, and a photograph album was used to help the subject estimate the portions consumed. Details of study methods have been described by Molina et al. [22].

The dietary variable used in the analysis was the daily consumption of each food in grams or milliliters. For the identification of the dietary patterns the 75 items of the FFQ were aggregated into 48 groups considering the similarity of the nutritional composition and the dietary habits of the municipality under study (Table 1). The food items cited by at least $80 \%$ of the subjects (for example, rice, beans, banana, chicken, beef, eggs and nondiet sodas) were kept separate.

\section{Statistical analysis}

The method of principal component analysis (PCA) was used to identify the dietary patterns, followed by the varimax method of orthogonal rotation to simplify interpretation of extracted factors. Estimation was based on the correlation matrix. The appropriateness of the dataset for applying the PCA was confirmed by the Kaiser-MeyerOlkin (KMO) measure of sampling adequacy and the Bartlett test of sphericity [23]. The number of retained factors was defined based on the following criteria: components with eigenvalues higher than 1.0 (indicating that the factor explains more of the total variance than each of the original variables separately), the Cattell scree plot and the conceptual meaning of the patterns identified [9]. Each principal component was interpreted based on foods with factor loadings (correlation coefficients between the dietary variables and the factors) $\geq 0.3$ or $\leq-0.3$, which are considered to make an important contribution to the pattern $[8,12]$. Negative loadings within a component indicate an inverse association of the food item and positive loadings indicate a direct association [15].

To determine the stability of the factors the set of observations was divided at random into two sub-sets and the same criterion was applied to each one of them. The factorial structures detected for the subgroups were compared to those of the entire sample. The principal components were labeled on the basis of the nutritional composition of foods of each factor. Each individual received a score for each retained factor, calculated by summing the standardized values of the items (food groups) weighted by their absolute scoring coefficients (factor loadings). The dietary patterns were categorized into quartiles. The upper quartile of the distribution represented the greatest adherence to the pattern.

Poisson regression with robust estimation of variance was used in bivariate and multivariable analysis to estimate the prevalence ratios (PR) of the independent variables (socioeconomic and demographic factors) in relation to the outcomes, with the dependent variables (dietary patterns) being classified as dichotomous: 1 st, $2^{\text {nd }}$ and $3^{\text {rd }}$ quartiles of consumption and high consumption ( $4^{\text {th }}$ quartile). We 
Table 1 Description of the $\mathbf{4 8}$ food groups used in the analysis of dietary patterns of the 1978/79 Ribeirão Preto birth cohort (4th phase)

\begin{tabular}{|c|c|}
\hline Food group & Item \\
\hline $\begin{array}{l}\text { Whole dairy } \\
\text { products }\end{array}$ & $\begin{array}{l}\text { Whole milk, whole yogurt with or without fruit, } \\
\text { yellow cheese, curd cheese, cream cheese }\end{array}$ \\
\hline $\begin{array}{l}\text { Low-fat dairy } \\
\text { products }\end{array}$ & $\begin{array}{l}\text { Skimmed milk/semi-skimmed milk, skimmed } \\
\text { yogurt, white cheese }\end{array}$ \\
\hline Whole grain bread & Whole wheat bread/whole rye bread \\
\hline White bread & $\begin{array}{l}\text { French bread, loaf, sliced loaf, bun, cheese bread, } \\
\text { others }\end{array}$ \\
\hline Cookies & Sweet cookies, salty cookies, toasts \\
\hline Breakfast cereals & Breakfast cereals, oatmeal, granola \\
\hline Margarine & Margarine, light margarine, butter \\
\hline Mayonnaise & Mayonnaise \\
\hline Rice & White rice \\
\hline Fried Potato & $\begin{array}{l}\text { French fries, chips, fried manioc, fried polenta } \\
\text { (fried corn mush) }\end{array}$ \\
\hline Non-fried potato & $\begin{array}{l}\text { Potato, manioc, cassava, polenta (corn mush), } \\
\text { sweet potato, corn }\end{array}$ \\
\hline Pasta & Pastas \\
\hline Salty snacks & Fried snacks, salty cake, salty pie, pizza \\
\hline Flours & $\begin{array}{l}\text { Farofa (fried manioc flour with butter or margarine } \\
\text { and salt), corn flour }\end{array}$ \\
\hline Orange & Orange, tangerine \\
\hline Banana & Banana \\
\hline Apple & Apple, pear \\
\hline Papaya/melon & Papaya, melon, watermelon \\
\hline Other fruits & $\begin{array}{l}\text { Grape, pineapple, guava, avocado, mango, } \\
\text { persimmon, other fruits }\end{array}$ \\
\hline Fruit juice & Orange juice, other fruit juices \\
\hline Bean & Bean \\
\hline Other legumes & Peas, lentils, others \\
\hline Leafy vegetables & $\begin{array}{l}\text { Lettuce, endive, watercress, arugula, chicory, } \\
\text { cabbage, chard, kale, spinach }\end{array}$ \\
\hline Other vegetables & Beet, pod, chayote, zucchini, eggplant \\
\hline Tomato & Tomato \\
\hline Broccoli & Broccoli, cauliflower \\
\hline Soup & Soups \\
\hline Beef & Beef with or without fat \\
\hline Pork meat & Pork meat with or without fat \\
\hline Bacon & Bacon, lard, crackling \\
\hline Chicken & Chicken meat, chester, turkey meat \\
\hline Fish & Fish \\
\hline Organ meat & Organ meats from cattle, poultry or pork \\
\hline Sea food & Shrimp, prawn, other sea food \\
\hline Cold cuts & Sausage, ham, mortadela, salami \\
\hline Egg & Fried egg, boiled egg \\
\hline Coffee & Coffee with or without sugar \\
\hline
\end{tabular}

Table 1 Description of the $\mathbf{4 8}$ food groups used in the analysis of dietary patterns of the 1978/79 Ribeirão Preto birth cohort (4th phase) (Continued)

\begin{tabular}{ll}
\hline Teas & Black tea, herbal tea \\
Beer & Beer \\
Liquors & $\begin{array}{l}\text { Cachaça (Brazilian rum made with sugar cane), } \\
\text { whisky, other liquors }\end{array}$ \\
Wine & Wine \\
Industrialized fruit & Industrialized fruit juices \\
juices & \\
Diet sodas & Diet sodas, light sodas \\
Soda & Soda, pop, coke \\
Honey & Honey, jelly \\
Desserts & Cakes, pies, parfaits, ice cream, milk shake, \\
& pudding, fruit sweets \\
Chocolate & $\begin{array}{l}\text { Chocolates, brigadeiro (Brazilian sweet made with } \\
\text { condensed milk and chocolate) }\end{array}$ \\
Nuts/seeds & Cashew nut, peanut, nuts
\end{tabular}

used Poisson regression to estimate the PR instead of the odds ratio because when the outcome is not a rare event $(>10 \%)$ by using odds ratio we tend to overestimate associations [24]. Variables whose p-values were $<0.20$ were included in the multivariable models. Interaction terms between sex and social mobility were tested and when significant models were presented stratified by sex. Since schooling is highly correlated with income, models with and without adjustment for schooling were fitted. Adjustment for schooling at two points in life may inadequately remove the possible effect of social mobility (measured by means of changes in income) on the dietary patterns. Estimates of $95 \%$ confidence intervals $(\mathrm{CI})$ of the PR were also calculated. The level of significance was set at 0.05 . The statistical analyses were performed using the Stata software, version 10.0. To test for consistency, analyses were also performed using per capita family income.

\section{Results}

The study sample consisted of $52.2 \%$ women, $67.9 \%$ singles, and $66.3 \%$ whites. Only $15.4 \%$ had up to eight years of schooling, while among their mothers this percentage was $73.0 \%$ at the time of their birth. The young adults also reported a higher current family income than the family income at the time of their birth, with the value being lower than three MW only in $10.6 \%$ of cases. Despite this, however, only $18.9 \%$ of the participants presented ascending social mobility (Table 2 ).

The KMO coefficient (0.7448) and the Bartlett test of sphericity $(\mathrm{p}<0.001)$ indicated satisfactory confidence for the execution of factor analysis. Sixteen factors with eigenvalues $\geq 1.0$ were retained and the inflexion of the scree plot indicated three factors. Analysis of the conceptual meaning of these factors identified four principal 
Table 2 Socioeconomic and demographic characteristics of 23 to 25 -year-old adults of the Ribeirão Preto birth cohort (4th phase: 2002-2004) according to sex

\begin{tabular}{|c|c|c|c|c|}
\hline \multirow{2}{*}{ Characteristics } & Women $(n=1,062)$ & Men $(n=972)$ & \multirow[b]{2}{*}{$p$ value } & \multirow{2}{*}{$\frac{\text { Total }(\mathrm{n}=2,034}{\mathrm{n}(\%)}$} \\
\hline & n (\%) & n (\%) & & \\
\hline \multicolumn{5}{|l|}{ Skin color } \\
\hline White & $731(68.8)$ & $618(63.6)$ & 0.086 & $1,349(66.3)$ \\
\hline Black & $45(4.3)$ & $43(4.4)$ & & $88(4.3)$ \\
\hline Mullato & $272(25.6)$ & $295(30.4)$ & & $567(27.9)$ \\
\hline Yellow & $14(1.3)$ & $16(1.7)$ & & $30(1.5)$ \\
\hline \multicolumn{5}{|l|}{ Schooling in adulthood (years) } \\
\hline $0-8$ & $156(14.7)$ & $158(16.3)$ & 0.173 & $314(15.4)$ \\
\hline $9-11$ & $521(49.1)$ & $499(51.3)$ & & $1020(50.2)$ \\
\hline$\geq 12$ & $385(36.2)$ & $315(32.4)$ & & $700(34.4)$ \\
\hline \multicolumn{5}{|c|}{ Maternal schooling at birth (years) ${ }^{a}$} \\
\hline $0-4$ & $477(45.8)$ & $432(45.4)$ & 0.598 & $909(45.6)$ \\
\hline $5-8$ & $296(28.4)$ & $251(26.4)$ & & $547(27.4)$ \\
\hline $9-11$ & $163(15.6)$ & $162(17.0)$ & & $325(16.3)$ \\
\hline$\geq 12$ & $106(10.2)$ & $107(11.2)$ & & $213(10.7)$ \\
\hline \multicolumn{5}{|l|}{ Marital status } \\
\hline Married/Cohabiting & $401(37.8)$ & $251(25.8)$ & $<0.001$ & $652(32.1)$ \\
\hline Single & $661(62.2)$ & $721(74.2)$ & & $1,382(67.9)$ \\
\hline \multicolumn{5}{|c|}{ Family income in adulthood (MW) } \\
\hline$<3.0$ & $125(11.8)$ & $90(9.3)$ & $<0.001$ & $215(10.6)$ \\
\hline $3.0-4.9$ & $251(23.6)$ & $207(21.3)$ & & $458(22.5)$ \\
\hline $5.0-9.9$ & $340(32.0)$ & $283(29.1)$ & & $623(30.6)$ \\
\hline $10.0-19.9$ & $177(16.7)$ & $219(22.5)$ & & $396(19.5)$ \\
\hline$\geq 20.0$ & $79(7.4)$ & $113(11.6)$ & & $192(9.4)$ \\
\hline Missing & $90(8.5)$ & $61(6.2)$ & & $150(7.4)$ \\
\hline \multicolumn{5}{|l|}{ Family income at birth (MW) } \\
\hline$\leq 1.0$ & $168(15.8)$ & $137(15.0)$ & 0.198 & $305(15.0)$ \\
\hline $1.1-3.0$ & $307(28.9)$ & $289(29.7)$ & & $596(29.3)$ \\
\hline $3.1-6.0$ & $200(18.8)$ & $207(21.3)$ & & $407(20.0)$ \\
\hline $6.1-10.0$ & $86(8.1)$ & $86(8.9)$ & & $172(8.5)$ \\
\hline$>10.0$ & $92(8.7)$ & $96(9.9)$ & & $188(9.2)$ \\
\hline Missing & $209(19.7)$ & $157(16.2)$ & & $366(18.0)$ \\
\hline \multicolumn{5}{|c|}{ Number of people in the household } \\
\hline 1 & $19(1.8)$ & $16(1.7)$ & 0.795 & $35(1.7)$ \\
\hline $2-4$ & $712(67.0)$ & $640(65.9)$ & & $1,352(66.5)$ \\
\hline$\geq 5$ & $331(31.2)$ & $316(32.5)$ & & $647(31.8)$ \\
\hline \multicolumn{5}{|l|}{ Children in the household } \\
\hline Yes & $708(66.7)$ & $774(79.6)$ & $<0.001$ & $1,482(72,9)$ \\
\hline No & $354(33.3)$ & 198 (20.4) & & $552(27,1)$ \\
\hline
\end{tabular}


Table 2 Socioeconomic and demographic characteristics of 23 to 25 -year-old adults of the Ribeirão Preto birth cohort (4th phase: 2002-2004) according to sex (Continued)

\begin{tabular}{|c|c|c|c|c|}
\hline \multicolumn{5}{|l|}{ Social mobility ${ }^{b}$} \\
\hline Poor - poor & $171(21.9)$ & 135 (17.6) & 0.138 & 306 (19.8) \\
\hline $\begin{array}{l}\text { Poor - not poor } \\
\text { (ascending mobility) }\end{array}$ & $144(18.5)$ & 149 (19.4) & & 293 (18.9) \\
\hline $\begin{array}{c}\text { Not poor - poor } \\
\text { (descending mobility) }\end{array}$ & $111(14.2)$ & $103(13.4)$ & & $214(13.8)$ \\
\hline Not poor - not poor & $354(45.4)$ & 381 (49.6) & & $735(47.5)$ \\
\hline
\end{tabular}

MW, minimum wages: monthly MW at birth in 1978 was equivalent to US\$ 84.0, MW in 2003 was equivalent to US\$ 89.8 .

$\mathrm{p}$ value based on the chi-square test.

${ }^{a}$ Total $\mathrm{n}=1,994, \mathrm{n}$ of men $=952, \mathrm{n}$ of women $=1,042$.

${ }^{b}$ Total $n=1,548, n$ of men $=768$, $n$ of women $=780$.

dietary patterns, which explained $20.92 \%$ of the total variance. Only these four retained patterns presented eigenvalues $\geq 1.5$ (Table 3 ). The factorial structures detected for the subgroups were similar to those of the entire sample, confirming the stability of the factors.

The dietary patterns were defined as follows: healthy (vegetables, fruits, peas and other legumes, fish, non-fried potatoes, manioc and polenta, chicken and breakfast cereals); traditional Brazilian (beans, rice, margarine and beef and a negative factor loading for low-fat dairy foods, whole grain bread and diet sodas); bar (alcoholic beverages, salty snacks, pork meat, sausages, eggs, bacon, seafood and mayonnaise) and energy-dense (desserts, white bread, cookies, chocolates, popcorn/chips, fried potatoes, manioc and polenta and whole milk dairy products). The healthy and traditional Brazilian patterns explained the greatest proportion of total variance $(6.56 \%$ and $5.15 \%$, respectively) (Table 3).

After adjustment in multivariable analysis, women and individuals with higher schooling in adulthood ( $\geq 12$ years) showed greater adherence to the healthy pattern. Men, mullatos, those who have children and living in households with $\geq 2$ members showed the highest adherence to the traditional Brazilian pattern, whereas individuals with higher schooling in adulthood ( $\geq 12$ years), higher family income in adulthood $(\geq 20 \mathrm{MW})$ and higher family income at birth $(\geq 6.1 \mathrm{MW})$ showed lower adherence. Men and individuals with lower schooling ( $\leq 8$ years) showed greater adherence to the bar pattern. The energy-dense pattern was not associated with any of the variables investigated (Table 4).

Social mobility was not associated with the healthy, traditional Brazilian and bar patterns (Table 5). The results for social mobility in the models without adjustment for schooling were similar to those found for the analysis with adjustment for schooling. A significant interaction between sex and social mobility $(\mathrm{p}=0.009)$ was detected only for the traditional Brazilian dietary pattern. Among women and men, those who were not poor at birth and remained so in adulthood, the category 'not poor - not poor', showed lower adherence to this pattern, with or without adjustment for schooling (Table 6).

In analysis using per capita family income results did not change appreciably.

\section{Discussion}

Four principal dietary patterns were identified among the 2,034 young adults of the Ribeirão Preto birth cohort, denoted healthy, traditional Brazilian, bar and energy-dense. The variance explained by these factors $(20.92 \%)$ was lower than that reported in other studies which also retained four components $[17,25]$. The decision to include a large number of food items in the principal component analysis may have contributed to the lower percentage of explanation of total variance $[9,12]$. In the adjusted analysis, women and individuals with higher schooling ( $\geq 12$ years) in adult life showed greater adherence to the healthy pattern. The highest adherence to the traditional Brazilian pattern was detected for men, mullatos, households with $\geq 2$ members, and for those who have children, while individuals with higher schooling in adulthood ( $\geq 12$ years), higher family income in adulthood $(\geq 20 \mathrm{MW})$ and higher family income at birth $(\geq 6.1 \mathrm{MW})$ showed lower adherence. The bar pattern was positively associated with male sex and low schooling ( $\leq 8$ years). The energydense pattern was not associated with any of the variables investigated. Social mobility was associated with the traditional Brazilian pattern. Men and women who were not poor at birth and remained so in adulthood showed lower adherence to this pattern.

The dietary pattern denoted healthy explained the greatest percentage of variance. Its composition is similar to that of other patterns reported in the literature with the same denomination [5,10,26-28] or even with others such as 'prudent' [15,25,29], 'nutrient dense' [30] and 'health aware' [31]. This pattern is characterized by the presence of foods rich in vitamins, minerals, fibers, and unsaturated fats and with low contents of sugars, 
Table 3 Distribution of factor loadings of the principal dietary patterns identified among 23 to 25 -year-old adults of the Ribeirão Preto birth cohort (4th phase: 2002-2004)

\begin{tabular}{|c|c|c|c|c|}
\hline \multirow{2}{*}{ Food groups } & \multicolumn{4}{|c|}{ Dietary patterns } \\
\hline & Healthy & Traditional Brazilian & Bar & Energy-dense \\
\hline Leafy vegetables & 0.585 & & & \\
\hline Papaya, melon & 0.522 & & & \\
\hline Apple, pear & 0.495 & & & \\
\hline Yellow vegetables & 0.484 & & & \\
\hline Broccoli & 0.458 & & & \\
\hline Fish & 0.446 & & & \\
\hline Tomato & 0.421 & & & \\
\hline Potato, manioc and polenta, not fried & 0.398 & & & \\
\hline Orange, tangerine & 0.389 & & & \\
\hline Chicken & 0.358 & & & \\
\hline Breakfast cereals & 0.352 & & & \\
\hline Banana & 0.335 & & & \\
\hline Fruit juice & 0.318 & & & \\
\hline Peas, lentils & 0.312 & & & \\
\hline Beans & & 0.695 & & \\
\hline Rice & & 0.690 & & \\
\hline Margarine & & 0.340 & & \\
\hline Beef & & 0.301 & & \\
\hline Low-fat dairy foods & & -0.397 & & \\
\hline Whole grain breads & & -0.346 & & \\
\hline Diet/light sodas & & -0.336 & & \\
\hline Beer & & & 0.592 & \\
\hline Salty snacks & & & 0.519 & \\
\hline Distilled beverages (Brazilian rum - cachaça, whiskey, vodka) & & & 0.479 & \\
\hline Porkmeat & & & 0.402 & \\
\hline Sausages & & & 0.351 & \\
\hline Eggs & & & 0.343 & \\
\hline Bacon & & & 0.342 & \\
\hline Seafood & & & 0.335 & \\
\hline Mayonnaise & & & 0.308 & \\
\hline Desserts, cakes, pies, ice cream, sweets & & & & 0.572 \\
\hline White breads, croissant, cheese bread & & & & 0.451 \\
\hline Sweet or salty cookies, toast & & & & 0.449 \\
\hline Chocolates & & & & 0.434 \\
\hline Popcorn, chips & & & & 0.386 \\
\hline Fried potato, manioc and polenta & & & & 0.345 \\
\hline Whole milk dairy products & & & & 0.303 \\
\hline Explained variance (\%) & 6.56 & 5.15 & 4.78 & 4.43 \\
\hline Eigenvalue & 3.15 & 2.47 & 2.29 & 2.12 \\
\hline
\end{tabular}

Only foods with factor loadings $\geq 0.3$ or $\leq-0.3$ were shown.

Total explained variance $=20.92 \%$. 
Table 4 Non-adjusted and adjusted prevalence ratios (PR) and confidence intervals $(95 \% \mathrm{Cl})$ for the association of socioeconomic and demographic variables with the dietary patterns identified among 23 to 25-year-old adults of the Ribeirão Preto birth cohort (4th phase: 2002-2004)

\begin{tabular}{|c|c|c|c|c|c|c|c|c|}
\hline \multirow[b]{2}{*}{ Variable } & \multicolumn{2}{|c|}{ Healthy } & \multicolumn{2}{|c|}{ Traditional Brazilian } & \multicolumn{2}{|c|}{ Bar } & \multicolumn{2}{|c|}{ Energy dense } \\
\hline & $\begin{array}{c}\text { Non-adjusted PR } \\
(95 \% \mathrm{Cl})\end{array}$ & $\begin{array}{c}\text { Adjusted PR } \\
(95 \% \mathrm{Cl})\end{array}$ & $\begin{array}{c}\text { Non-adjusted PR } \\
(95 \% \mathrm{Cl})\end{array}$ & $\begin{array}{c}\text { Adjusted PR } \\
(95 \% \mathrm{Cl})\end{array}$ & Non-adjusted PR & $\begin{array}{c}\text { Adjusted PR } \\
(95 \% \mathrm{Cl})\end{array}$ & $\begin{array}{c}\text { Non-adjusted PR } \\
(95 \% \mathrm{Cl})\end{array}$ & $\begin{array}{c}\text { Adjusted PR } \\
(95 \% \mathrm{CI})\end{array}$ \\
\hline Sex & $p=0.011$ & $p=0.004$ & $p<0.001$ & $p<0.001$ & $p<0.001$ & $p<0.001$ & $p=0.625$ & - \\
\hline Female & Reference & Reference & Reference & Reference & Reference & Reference & Reference & - \\
\hline Male & $0.82(0.71-0.96)$ & $0.79(0.68-0.93)$ & $2.99(1.42-3.71)$ & $2.39(2.04-2.80)$ & $4.33(3.47-5.41)$ & $2.96(2.47-3.55)$ & $0.95(0.78-1.16)$ & - \\
\hline Skin color & $p=0.009$ & $p=0.391$ & $p<0.001$ & $p<0.001$ & $p=0.645$ & - & $p=0.103$ & $p=0.103$ \\
\hline White & Reference & Reference & Reference & Reference & Reference & - & Reference & Reference \\
\hline Black & $0.64(0.37-1.10)$ & $0.86(0.56-1.33)$ & $2.66(1.69-4.19)$ & $1.26(0.95-1.67)$ & $1.20(0.74-1.93)$ & - & $1.44(0.91-2.89)$ & $1.44(0.91-2.89)$ \\
\hline Mullato & $0.70(0.55-0.89)$ & $0.93(0.77-1.14)$ & $2.83(2.28-3.53)$ & $1.41(1.21-1.64)$ & $1.01(0.80-1.26)$ & - & $0.89(0.71-1.12)$ & $0.89(0.71-1.12)$ \\
\hline Yellow & $0.53(0.20-1.40)$ & $0.49(0.20-1.22)$ & $1.11(0.45-2.74)$ & $1.37(0.66-2.86)$ & $0.60(0.23-1.59)$ & - & $0.45(0.15-1.30)$ & $0.45(0.15-1.30)$ \\
\hline Schooling in adulthood (years) & $p<0.001$ & $p=0.068$ & $p<0.001$ & $p<0.001$ & $p=0.003$ & $p<0.001$ & $p=0.539$ & - \\
\hline $0-8$ & Reference & Reference & Reference & Reference & Reference & Reference & Reference & - \\
\hline $9-11$ & $1.59(1.13-2.23)$ & $1.34(0.99-1.80)$ & $0.61(0.47-0.79)$ & $0.91(0.77-1.07)$ & $0.62(0.47-0.83)$ & $0.67(0.55-0.82)$ & $0.95(0.71-1.27)$ & - \\
\hline$\geq 12$ & $2.59(1.84-3.66)$ & $1.51(1.07-2.14)$ & $0.13(0.09-0.18)$ & $0.47(0.34-0.65)$ & $0.79(0.59-1.06)$ & $0.72(0.56-0.93)$ & $0.86(0.63-1.17)$ & - \\
\hline Maternal schooling at birth (years) & $p<0.001$ & $p=0.271$ & $p<0.001$ & $p=0.160$ & $p=0.041$ & $p=0.165$ & $p=0.379$ & - \\
\hline $0-4$ & Reference & Reference & Reference & Reference & Reference & Reference & Reference & - \\
\hline $5-8$ & $1.35(1.05-1.73)$ & $1.17(0.95-1.42)$ & $0.55(0.43-0.70)$ & $0.84(0.71-1.01)$ & $1.27(0.99-1.63)$ & $1.23(1.02-1.48)$ & $1.10(0.86-1.40)$ & - \\
\hline $9-11$ & $1.61(1.20-2.14)$ & $1.18(0.93-1.49)$ & $0.35(0.25-0.48)$ & $0.85(0.65-1.12)$ & $1.24(0.93-1.66)$ & $1.09(0.86-1.37)$ & $0.91(0.68-1.23)$ & - \\
\hline$\geq 12$ & $2.20(1.59-3.04)$ & $1.30(0.97-1.73)$ & $0.14(0.08-0.25)$ & $0.72(0.43-1.19)$ & $1.54(1.10-2.14)$ & $1.08(0.80-1.44)$ & $0.81(0.56-1.16)$ & - \\
\hline Marital status & $p=0.002$ & $p=0.475$ & $p=0.002$ & $p=0.218$ & $p<0.001$ & $p=0.140$ & $p=0.595$ & - \\
\hline Single & Reference & Reference & Reference & Reference & Reference & Reference & Reference & - \\
\hline Married/Cohabiting & $0.71(0.56-0.88)$ & $0.93(0.75-1.14)$ & $1.39(1.13-1.72)$ & $0.89(0.74-1.07)$ & $0.66(0.53-0.83)$ & $0.87(0.72-1.05)$ & $0.94(0.76-1.17)$ & - \\
\hline Family income in adulthood (MW) & $p<0.001$ & $p=0.046$ & $p<0.001$ & $p=0.090$ & $p<0.001$ & $p=0.195$ & $p=0.372$ & - \\
\hline$<3.0$ & Reference & Reference & Reference & Reference & Reference & Reference & Reference & - \\
\hline $3.0-4.9$ & $0.77(0.52-1.15)$ & $0.74(0.54-1.02)$ & $0.82(0.59-1.15)$ & $0.93(0.74-1.06)$ & $0.90(0.61-1.33)$ & $0.92(0.69-1.23)$ & $0.83(0.58-1.19)$ & - \\
\hline $5.0-9.9$ & $1.07(0.74-1.55)$ & $0.85(0.63-1.15)$ & $0.52(0.38-0.73)$ & $0.93(0.75-1.15)$ & $1.10(0.76-1.59)$ & $1.06(0.80-1.40)$ & $0.80(0.57-1.13)$ & - \\
\hline $10.0-19.9$ & $1.54(1.05-2.27)$ & $1.02(0.73-1.42)$ & $0.29(0.20-0.43)$ & $0.86(0.69-1.09)$ & $1.10(0.74-1.63)$ & $0.94(0.68-1.29)$ & $0.74(0.51-1.08)$ & - \\
\hline$\geq 20$ & $2.03(1.32-3.13)$ & $1.08(0.74-1.56)$ & $0.13(0.07-0.23)$ & $0.57(0.33-0.99)$ & $2.07(1.35-3.20)$ & $1.27(0.90-1.81)$ & $0.61(0.39-0.97)$ & - \\
\hline Missing & $0.78(0.46-1.31)$ & $0.68(0.44-1.03)$ & $0.69(0.45-1.08)$ & $0.99(0.74-1.32)$ & $1.23(0.76-1.99)$ & $1.12(0.79-1.59)$ & $0.91(0.57-1.44)$ & - \\
\hline
\end{tabular}


Table 4 Non-adjusted and adjusted prevalence ratios (PR) and confidence intervals $(95 \% \mathrm{Cl})$ for the association of socioeconomic and demographic variables with the dietary patterns identified among 23 to 25-year-old adults of the Ribeirão Preto birth cohort (4th phase: 2002-2004) (Continued)

\begin{tabular}{|c|c|c|c|c|c|c|c|c|}
\hline Family income at birth (MW) & $p=0.004$ & $p=0.787$ & $p<0.001$ & $p=0.006$ & $p=0.020$ & $p=0.207$ & $p=0.219$ & 一 \\
\hline$\leq 1.0$ & Reference & Reference & Reference & Reference & Reference & Reference & Reference & - \\
\hline $1.1-3.0$ & $1.09(0.78-1.52)$ & $0.93(0.71-1.22)$ & $0.78(0.59-1.04)$ & $0.99(0.83-1.19)$ & $1.04(0.75-1.45)$ & $1.00(0.78-1.28)$ & $1.07(0.79-1.47)$ & - \\
\hline $3.1-6.0$ & $1.37(0.98-1.94)$ & $0.95(0.71-1.28)$ & $0.44(0.32-0.62)$ & $0.83(0.65-1.05)$ & $1.03(0.72-1.47)$ & $0.93(0.71-1.2)$ & $1.02(0.73-1.44)$ & - \\
\hline $6.1-10.0$ & $1.35(0.87-2.08)$ & $0.80(0.56-1.15)$ & $0.18(0.10-0.31)$ & $0.57(0.35-0.94)$ & $1.51(0.99-2.30)$ & $1.23(0.88-1.71)$ & $1.00(0.65-1.53)$ & 一 \\
\hline$>10.0$ & $2.04(1.36-3.07)$ & $0.98(0.69-1.40)$ & $0.09(0.05-0.18)$ & $0.37(0.19-0.69)$ & $1.76(1.17-2.64)$ & $1.27(0.91-1.75)$ & $0.64(0.41-1.01)$ & - \\
\hline Missing & $1.10(0.76-1.59)$ & $0.89(0.66-1.20)$ & $0.49(0.35-0.69)$ & $0.82(0.65-1.03)$ & $1.22(0.85-1.75)$ & $1.16(0.87-1.51)$ & $0.88(0.62-1.25)$ & - \\
\hline Number of people in the household & $p=0.744$ & - & $p=0.003$ & $p=0.122$ & $p=0.137$ & $p=0.271$ & $p=0.774$ & - \\
\hline 1 & Reference & - & Reference & Reference & Reference & Reference & Reference & - \\
\hline $2-4$ & $1.26(0.65-2.47)$ & - & $8.54(1.23-59.12)$ & $6.97(1.02-47.57)$ & $0.65(0.42-1.01)$ & $0.73(0.48-1.11)$ & $1.25(0.64-2.43)$ & - \\
\hline$\geq 5$ & $1.23(0.62-2.42)$ & - & $9.57(1.38-66.38)$ & $7.21(1.06-49.18)$ & $0.71(0.45-1.11)$ & $0.78(0.51-1.20)$ & $1.27(0.64-2.49)$ & - \\
\hline Children in the household & $p=0.001$ & $p=0.435$ & $p<0.001$ & $p=0.007$ & $p=0.921$ & - & $p=0.365$ & - \\
\hline No & Reference & Reference & Reference & Reference & Reference & - & Reference & - \\
\hline Yes & $0.73(0.61-0.88)$ & $0.91(0.72-1.15)$ & $1.50(1.29-1.75)$ & $1.28(1.07-1.55)$ & $0.99(0.84-1.17)$ & - & $0.92(0.78-1.10)$ & - \\
\hline
\end{tabular}

MW, minimum wages: monthly MW at birth was equivalent to US\$ 84.0 MW in 1978 and to US\$ 89.8 in 2003.

p value for trend referring to the maximum likelihood ratio test obtained by Poisson regression.

a Adjusted for sex, skin color, maternal schooling at birth, schooling in adulthood, marital status, family income at birth, family income in adulthood, and presence of children in the household.

${ }^{b}$ Adjusted for sex, skin color, maternal schooling at birth, schooling in adulthood, marital status, family income at birth, family income in adulthood, number of people in the household and presence of children in

the household.

'Adjusted for sex, maternal schooling at birth, schooling in adulthood, marital status, family income at birth, family income in adulthood and number of people in the household.

${ }^{\mathrm{d}}$ Adjusted for skin color. 
Table 5 Non-adjusted and adjusted prevalence ratios (PR) and confidence intervals $(95 \% \mathrm{Cl})$ for the association of social mobility with the healthy, bar and energy dense dietary patterns identified in 23 to 25 -year-old adults of the Ribeirão Preto birth cohort (4th phase: 2002-2004)

\begin{tabular}{|c|c|c|c|c|c|c|}
\hline \multirow{3}{*}{ Social mobility } & \multicolumn{2}{|c|}{ Healthy pattern } & \multicolumn{2}{|c|}{ Bar pattern } & \multicolumn{2}{|c|}{ Energy dense pattern } \\
\hline & $\begin{array}{l}\text { Non-adjusted } \\
\text { PR }(95 \% \mathrm{Cl})\end{array}$ & $\begin{array}{c}\text { Adjusted } \\
\text { PR }(95 \% \mathrm{CI})^{\mathrm{a}}\end{array}$ & $\begin{array}{l}\text { Non-adjusted } \\
\text { PR }(95 \% \mathrm{Cl})\end{array}$ & $\begin{array}{c}\text { Adjusted } \\
\text { PR }(95 \% \mathrm{CI})^{\mathrm{b}}\end{array}$ & $\begin{array}{l}\text { Non-adjusted } \\
\text { PR }(95 \% \mathrm{Cl})\end{array}$ & $\begin{array}{c}\text { Adjusted } \\
\text { PR }(95 \% \mathrm{CI})^{\mathrm{c}}\end{array}$ \\
\hline & $p=0.001$ & $p=0.541$ & $p=0.185$ & $p=0.622$ & $p=0.331$ & $p=0.664$ \\
\hline Poor - poor & Reference & Reference & Reference & Reference & Reference & Reference \\
\hline Poor - not poor & $1.08(0.73-1.58)$ & $0.93(0.68-1.26)$ & $1.18(0.81-1.73)$ & $1.09(0.82-1.46)$ & $1.14(0.78-1.66)$ & $1.11(0.83-1.48)$ \\
\hline Not poor - poor & $0.91(0.59-1.41)$ & $0.82(0.58-1.17)$ & $0.95(0.62-1.45)$ & $0.88(0.64-1.22)$ & $0.92(0.61-1.41)$ & $0.97(0.70-1.33)$ \\
\hline Not poor - not poor & $1.62(1.19-2.22)$ & $1.01(0.76-1.36)$ & $1.31(0.96-1.80)$ & $0.99(0.75-1.33)$ & $1.23(0.90-1.69)$ & $1.13(0.86-1.49)$ \\
\hline
\end{tabular}

Total $n=1,549, n$ of men $=769, n$ of women $=780$.

$\mathrm{p}$ value for trend referring to the maximum likelihood ratio test obtained by Poisson regression.

adjusted for sex, skin color, maternal schooling at birth, schooling in adulthood, marital status and presence of children in the household.

${ }^{b}$ Adjusted for sex, maternal schooling at birth, schooling in adulthood, marital status and number of people in the household.

'Adjusted for skin color.

trans and saturated fats [25]. The traditional Brazilian pattern involved traditional foods of the Brazilian diet, as it was also observed in other studies $[3,6,14,15]$. In a similar study conducted on young adults (23 years) from Pelotas, Rio Grande do Sul, Brazil, Olinto et al. [16] defined a similar pattern as 'common Brazilian', and Gimeno et al. [17], in a study of adults aged 30 years or older from Ribeirão Preto, called it 'popular'. The 'traditional' denomination is habitually used in studies from other countries, but the foods that compose this diet vary according to the culture of each country [9].

The dietary pattern denoted bar consisted of alcoholic beverages and foods commonly served in bars. No pattern with this denomination was found in the literature. However, some studies have identified factors containing alcoholic beverages in their composition [9,16,26,31,32]. The fourth pattern identified was called energy-dense because it is rich in sugars and saturated and trans fats. Patterns with similar compositions have been designated in various ways in other studies: 'obesogenic' [17], 'energy dense' [30], 'snack' [15] and 'dairy foods and desserts' [6].

It should be pointed out that many studies have identified a pattern defined, in most cases, as western $[25,26,33]$, which represents a combination of the energydense and bar patterns considered in the present study. Rezazadeh, Rashidkhani and Omidvar [26] defined this combination as 'not healthy'. Positive associations between patterns with compositions similar to those of the energy-dense and bar patterns and unfavorable health outcomes such as obesity have been described in some studies $[9,14,30]$.

The differences in composition between patterns with the same denomination found in the literature, and the different denominations of factors of similar composition may be explained by the subjectivity inherent to the methods of principal component analysis [25]. In a review of this topic, Newby and Tucker [9] pointed out the following major decisions that should be made by an

Table 6 Non-adjusted and adjusted prevalence ratios (PR) and confidence intervals (95\% $\mathrm{Cl})$ for the association of social mobility with the traditional Brazilian dietary pattern stratified by sex, among 23 to 25 -year-old adults of the Ribeirão Preto birth cohort (4th phase: 2002-2004)

\begin{tabular}{|c|c|c|c|c|c|c|}
\hline \multirow[t]{3}{*}{ Social mobility } & \multicolumn{3}{|c|}{ Men } & \multicolumn{3}{|c|}{ Women } \\
\hline & $\begin{array}{c}\text { Non-adjusted } \\
\text { PR }(95 \% \mathrm{Cl})\end{array}$ & $\begin{array}{c}\text { Adjusted } \\
\text { PR }(95 \% \mathrm{CI})^{\mathrm{a}}\end{array}$ & $\begin{array}{c}\text { Adjusted } \\
\text { PR }(95 \% \mathrm{CI})^{\mathrm{b}}\end{array}$ & $\begin{array}{c}\text { Non-adjusted } \\
\text { PR }(95 \% \mathrm{Cl}) \\
\end{array}$ & $\begin{array}{c}\text { Adjusted } \\
\text { PR }(95 \% \mathrm{Cl})^{\mathrm{a}} \\
\end{array}$ & $\begin{array}{c}\text { Adjusted PR } \\
(95 \% \mathrm{Cl})^{\mathrm{b}}\end{array}$ \\
\hline & $\mathrm{p}<0.001$ & $p=033$ & $\mathrm{p}<0.001$ & $\mathrm{p}<0.001$ & $p=0.082$ & $p<0.001$ \\
\hline Poor - poor & Reference & Reference & Reference & Reference & Reference & Reference \\
\hline Poor - not poor & $0.59(0.37-0.94)$ & $0.90(0.69-1.16)$ & $0.83(0.64-1.07)$ & $0.62(0.36-1.05)$ & $0.86(0.56-1.32)$ & $0.83(0.54-1.28)$ \\
\hline Not poor - poor & $0.78(0.47-1.30)$ & $1.07(0.82-1.40)$ & $1.01(0.77-1.31)$ & $0.56(0.31-1.01)$ & $0.79(0.50-1.27)$ & $0.72(0.45-1.13)$ \\
\hline Not poor - not poor & $0.24(0.16-0.36)$ & $0.70(0.53-0.94)$ & $0.50(0.38-0.66)$ & $0.11(0.06-0.21)$ & $0.40(0.20-0.80)$ & $0.23(0.12-0.44)$ \\
\hline
\end{tabular}

Total $n=1,549, n$ of men $=769, n$ of women $=780$.

$\mathrm{p}$ value for trend referring to the maximum likelihood ratio test obtained by Poisson regression.

${ }^{a}$ Adjusted for skin color, number of people in the household, presence of children in the household, maternal schooling at birth, schooling in adulthood and marital status.

${ }^{b}$ Adjusted for skin color, number of people in the household, presence of children in the household and marital status. 
investigator which could influence the results: 1) which method to use for the investigation of food intake; 2) whether or not to group the food items; 3) how to treat the variables (grams/milliliters, \% total caloric value, etc.); 4) number of retained factors; 5) starting from what value the factor loading will be considered to be important for the component; 6) how the retained patterns will be denominated. Newby and Tucker [9] also emphasize the importance of considering the nutritional composition of the foods that constitute each retained factor when attributing names to the dietary patterns identified. In the present study, the authors followed this recommendation.

Female sex and schooling in adulthood $\geq 12$ years were found to be associated with the healthy dietary pattern. In contrast, men showed more adherence to the traditional Brazilian and bar patterns, as also observed in other studies that identified patterns of compositions similar to those studied here $[16,26]$. Differences in diet quality between sexes have been reported and it has been well established in the literature that women adhere more to healthy dietary patterns than men $[9,11,17,25,26]$. According to Newby and Tucker [9], this can be explained in part by the preoccupation of women with a good physical shape. A positive association between high schooling and income, and healthy food patterns has also been confirmed in other studies $[11,17,26,27]$.

Mullatos showed greater adherence to the traditional Brazilian pattern, as it was also reported in other studies $[3,16]$. The fact that beans, the most important food in this pattern, were the principal diet component for those with low socioeconomic status during the colonial period of Brazil might explain this result. Also in agreement with other Brazilian studies [16,17], better socioeconomic levels at present (schooling and family income) and at birth (family income) showed an inverse association with this dietary pattern. The determinants of food choices are complex [34], and although price is not the only factor guiding these choices, a low income can limit them [11,34]. Except for beef, the foods composing the pattern called traditional Brazilian in the present study are of low cost. It should also be pointed out that only four food items presented an important positive factor loading in this pattern, suggesting monotony in the diet of less privileged socioeconomic classes, as also observed in a similar study [16].

Low schooling in adulthood was associated with the bar pattern, in contrast to other studies that identified patterns containing alcoholic beverages in their composition, where those of high schooling tended to show greater adherence to this pattern $[16,30,35]$. Low schooling may contribute to unhealthy food choices, since education allows people to obtain information about health, especially healthy dietary patterns, with consequent improvement of dietary habits [26].
Although none of the socioeconomic or demographic variables investigated showed association with the energydense pattern in the present study, female sex and higher schooling in adulthood and income in other population groups were associated with patterns of similar composition $[16,17,30]$.

Social mobility was not associated with the healthy, bar and energy dense patterns. An interaction between sex and social mobility was detected only for the traditional Brazilian pattern. The category 'not-poor - not poor' showed lower adherence to the traditional Brazilian for both men and women. Similarly, young adults in the Brazilian city of Pelotas, of both sexes who were in the highest income tertile at birth and in adulthood (referred to as 'never poor'), showed lower adherence to the 'common Brazilian' pattern compared to those who belonged to the lowest tertile of income at birth and remained there in adulthood, termed 'always poor'. In the Pelotas study, the category 'poor - not poor' also showed greater adherence to the 'processed food' pattern compared to those who were 'always poor' [16]. Mishra et al. [31], studying British adults, found that those who held non-manual occupational activities and whose parents were also engaged in non-manual occupations at the time of their birth had healthier eating patterns than those who remained in the category manual as well as their parents.

In our study, the higher the number of people in the household the greater the adherence to the traditional Brazilian pattern. Also the adherence to this pattern was greater if the individual has had children. Demographic factors that take into account the number of household members have also been associated with some dietary patterns in other studies. For example, in Tehran, housing size $>20 \mathrm{~m}^{2} /$ head was positively associated with a healthy dietary pattern [26].

The results of the present study should be compared with caution to those of other investigations since methodological differences exist between studies and food choices depend on socioeconomic and cultural factors of each population. Thus, the results of the present investigation cannot be generalized and only represent the dietary patterns of the cohort studied, but not of the entire population of young adults from Ribeirão Preto, São Paulo, Brazil. This is due to the fact that the cohort comprises a small age group born in a couple of years (1978/79). Furthermore, the population composition changed from birth to adulthood due to migration.

Our study has some limitations. It should be pointed out that there were selective losses when the group of individuals followed up in the fourth phase of the study was compared to subjects who were not followed up. The follow-up rates were slightly higher for women and for individuals whose mothers had higher schooling at the time of their birth. Although statistically significant, 
these differences were small [19]. Additional limitations are those inherent to the methods of dietary surveys and the subjectivity of the PCA method for the definition of dietary patterns [9]. Furthermore, PCA do not assume exactly an ordinal response option. In addition, the variability explained by the four retained components was relatively low (20.92\%).

The FFQ used in this study was not validated in the present population, which is a limitation. However, it has been validated in second and third generation Japanese-Brazilian adults from São Paulo who have similar dietary habits to those of our population $[22,36]$.

However, dietary surveys are widely used in epidemiological studies and, in the present investigation, the FFQ was applied by nutritionists with the assistance of a photo album in order to facilitate the estimation of portion sizes. In addition, all subjective choices typical of the PCA method were based on scientific knowledge and on an extensive review of the literature.

Thus, the present study allowed the identification of four major dietary patterns in this population of young adults and the identification of socioeconomic and demographic differences associated with food choices. In addition, it was possible to understand how socioeconomic factors existing at birth were associated with dietary patterns in young adulthood.

\section{Conclusions}

Four principal dietary patterns were identified: healthy, traditional Brazilian, bar and energy-dense. Women and individuals with higher schooling showed greater adherence to the healthy pattern. The highest adherence to the traditional Brazilian pattern occurred for men, mullatos, households with $\geq 2$ members and for those who have children, while individuals with higher schooling in adulthood, higher family income in adulthood, higher family income at birth and who were not poor at birth and remained so in adulthood showed lower adherence to this pattern. The bar pattern was positively associated with male sex and low schooling. Finally, the energy-dense pattern was not associated with any of the variables investigated.

\section{Abbreviations \\ MW: Minimum wages; FFQ: Food frequency questionnaire; KMO: Kaiser-Meyer- Olkin; PR: Prevalence ratios.}

\section{Competing interests}

The authors declare that they have no competing interests.

\section{Authors' contributions}

SPMA participated in the stages of data analysis and was responsible for writing the manuscript; AAMS participated in the stage of data analysis and critical review of the manuscript; GK and MG contributed to the discussion of the data and critical revision of the manuscript; $H B$ and $M A B$ were responsible for the original design of the project and participated in the discussion stages of the data and critical revision of the manuscript. All authors read and approved the final manuscript.

\section{Acknowledgments}

Research was supported by CNPQ (Portuguese acronym for the National Research Council - Conselho Nacional de Desenvolvimento Científico e Tecnológico), University of São Paulo and FAPESP (Portuguese acronym for the São Paulo State Resarch Council - Fundação de Amparo à Pesquisa do Estado de São Paulo, protocol number 00/09508-7.

\section{Author details}

'Department of Nutritional Sciences, State University of Ceará, Coordination of Nutrition Course, Av. Paranjana, 1700, Itapery, Fortaleza, CE 60.740-000, Brazil. ' ${ }^{2}$ Department of Public Health, Federal University of Maranhão, Rua Barão de Itapary, 155, Centro, São Luís, Maranhão 65.020-070, Brazil.

${ }^{3}$ Department of Applied Social Nutrition, Federal University of Rio de Janeiro, Av. Brigadeiro Trompowsky, s/n, bloco J, $2^{\circ}$ andar, sala 29, Cidade Universitária, Rio de Janeiro 21.941-590, Brazil. ${ }^{4}$ Department of Pediatrics and Puericulture, Faculty of Medicine, Federal University of Rio Grande do Sul, Rua Ramiro Barcellos, 2350, Bonfim, Porto Alegre, Rio Grande do Sul 90.035-003, Brazil. ${ }^{5}$ Department of Puericulture and Pediatrics, Faculty of Medicine de Ribeirão Preto, University of São Paulo, Av. Bandeirantes, 3900, Monte Alegre, Ribeirão Preto, São Paulo 14.049-900, Brazil.

Received: 24 October 2013 Accepted: 27 May 2014

Published: 26 June 2014

\section{References}

1. Stringhini S, Sabia S, Shipley M, Brunner E, Nabi H, Kivimaki M, Sign-Manoux A: Association of socioeconomic position with health behaviors and mortality. JAMA 2012, 303:1159-1166.

2. Perozzo G, Olinto MTA, Dias-da-Costa JS, Henn RL, Sarriera J, Pattussi MP: Associação dos padrões alimentares com obesidade geral e abdominal em mulheres residentes no Sul do Brasil. Cad Saude Publica 2008, 24:2427-2430.

3. Sichieri R, Castro JFG, Moura AS: Fatores associados ao padrão de consumo alimentar da população brasileira. Cad Saude Publica 2003, 19(Suppl 1):47-53.

4. Hoffmann K, Schulze MB, Schienkiewitz A, Nöthlings U, Boeing H: Application of a new statistical method to derive dietary patterns in nutritional epidemiology. Am J Epidemiol 2004, 159:935-944.

5. Alves ALS, Olinto MTA, Dias-da-Costa JS, Bairros FS, Balbinotti MAA: Padrões alimentares de mulheres adultas residentes em áreas urbanas no Sul do Brasil. Rev Saude Publica 2006, 40:865-873.

6. Neumann AICP, Martins IS, Marcopito LF, Araujo EAC: Padrões alimentares associados a fatores de risco para doenças cardiovasculares entre residentes de um município brasileiro. Rev Panam Salud Publica 2007, 22:329-339.

7. Hu FB: Dietary pattern analysis: a new direction in nutritional epidemiology. Curr Opin Lipidol 2002, 13:3-9.

8. Hearty AP, Gibney MJ: Comparison of cluster and principal component analysis techniques to derive dietary patterns in Irish adults. Br J Nutr 2008, 101:598-608.

9. Newby PK, Tucker KL: Empirically derived eating patterns using factor or cluster analysis: a review. Nutr Rev 2004, 62:177-203.

10. Slattery ML: Defining dietary consumption: is the sum greater than its parts? Am J Clin Nutr 2008, 88:14-15.

11. Lenz A, Olinto MTA, Dias-da-Costa JS, Alves AL, Balbinotti M, Pattussi MP, Bassani DG: Socioeconomic patterns of women living, demographic and lifestyle factors associated with dietary of women living in Southern Brazil. Cad Saude Publica 2009, 25:1297-1306.

12. Costacou T, Bamia C, Ferrari P, Riboli E, Trichopoulos D, Trichopoulou A: Tracing the Mediterranean diet through principal components and cluster analyses in the Greek population. Eur J Clin Nutr 2003, 57:1378-1385.

13. Hare-Brunn H, Togo P, Andersen LB, Heitmann BL: Adult food intake patterns are related to adult and childhood socioeconomic status. J Nutr 2011, 141(5):928-934.

14. Sicheiri R: Dietary patterns and their associations with obesity in the Brazilian city of Rio de Janeiro. Obes Res 2002, 10:42-48.

15. Marchioni DML, Latorre MRDO, Eluf-Neto J, Wünsch-Filho V, Fisberg RM: Identification of dietary patterns using factor analysis in an epidemiological study in São Paulo. Sao Paulo Med J 2005, 123:124-127. 
16. Olinto MTA, Willett WC, Gigante DP, Victora CG: Sociodemographic and lifestyle characteristics in relation to dietary patterns among young Brazilian adults. Public Health Nutr 2010, 14:150-159.

17. Gimeno SGA, Mondini L, Moraes SA, Freitas ICM: Padrões de consumo de alimentos e fatores associados em adultos jovens de Ribeirão Preto, São Paulo, Brasil: Projeto OBEDIAPR. Cad Saude Publica 2011, 27:533-545.

18. Olinto MTA, Gigante DP, Horta B, Silveira V, Oliveira I, Willett W: Major dietary patterns and cardiovascular risk factors among young Brazilian adults. Eur J Nutr 2012, 51:281-291.

19. Barbieri MA, Bettiol H, Silva AAM, Cardoso VC, Simões VM, Gutierrez MR, Castro JA, Viana ES, Foss MC, Dos Santos JE, Queiroz RG: Health in early adulthood: the contribution of the 1978/79 Ribeirão Preto birth cohort. Braz J Med Biol Res 2006, 39:1041-1055.

20. Barbieri MA, Gomes UA, Barros Filho AA, Bettiol H, Almeida LEA, Silva AAM: Saúde perinatal em Ribeirão Preto, SP, Brasil: a questão do método. Cad Saude Publ 1989, 1989(5):376-387.

21. Cardoso MA, Kida AA, Tomita LY, Stocco PR: Reproducibility and validity of a food frequency questionnaire among women of Japanese ancestry living in Brazil. Nutr Res 2001, 21:725-733.

22. Molina MC, Bettiol H, Barbieri MA, Silva AA, Conceição SI, Dos Santos JE: Food consumption by young adults living in Ribeirão Preto, SP, 2002/ 2004. Braz J Med Biol Res 2007, 40:1257-1266.

23. Hair JF, Black WC, Babin BJ, Anderson RE: Multivariate Data Analysis. 7th edition. Prentice Hall: Englewood Cliffs; 2009.

24. Barros AJ, Hirakata VN: Alternatives for logistic regression in cross-sectional studies: an empirical comparison of models that directly estimate the prevalence ratio. BMC Med Res Methodol 2003, 3:21.

25. Naja F, Nasreddine L, Italini L, Chamieh MC, Adra N, Sibai AM, Hwalla N: Dietary patterns and their association with obesity and sociodemographic factors in a national sample of Lebanese adults. Public Health Nutr 2011, 14:1570-1578.

26. Rezazadeh A, Rashidkhani B, Omidvar N: Association of major dietary patterns with socioeconomic and lifestyle factors of adult women living in Tehran, Iran. Nutrition 2010, 26:337-341.

27. Perrin AE, Dallongeville J, Ducimetière P, Ruidavest JB, Schlienger JL, Arvelier D, Simon C: Interactions between traditional regional determinants and socioeconomic status on dietary patterns in a sample of French men. Br J Nutr 2005, 93:109-114.

28. Fonseca MJ, Gaio R, Lopes C, Santos AC: Association between dietary patterns and metabolic syndrome in a sample of Portuguese adults. Nutr J 2012, 11:64

29. Denova-Gutiérrez E, Castañón S, Talayera JO, Flores M, Macías N, RodríquezRamírez S, Flores YN, Salmerón J: Dietary patterns are associated with different indexes of adiposity and obesity in an urban Mexican population. J Nutr 2011. doi:10.3945/jn.110.132332.

30. Langsetmo L, Poliquin S, Hanley DA, Prior JC, Barr S, Anastassiades T, Towheed T, Goltzman D, Kreiger N, CaMos Research Group: Dietary patterns in Canadian men and women ages 25 and older: relationship to demographics, body mass index and bone mineral density. BMC Musculoskelet Disord 2010, 11:20. doi:10.1186/1471-2474-11-20.

31. Mishra GD, Prynne CJ, Paul AA, Greenberg DC, Bolton-Smith C: The impact of intergeneration social and regional circumstances on dietary intake patterns of British adults: results from the 1946 British Birth Cohort. Public Health Nutr 2004, 7:737-744.

32. Newby PK, Muller D, Hallfrisch J, Andres R, Tucker KL: Food patterns measured by factor analysis and anthropometric changes in adults. Am J Clin Nutr 2004, 80:504-513.

33. Sánchez-Villegas A, Delgado-Rodríguez M, Martínez-González MA, IralaEstévez J: Gender, age, socio-economic and lifestyle factors associated with major dietary patterns in the Spanish project SUN (Seguimiento Universidad de Navarra). Eur J Clin Nutr 2003, 57:285-292.
34. Darmon N, Drewnowski A: Does social class predict diet quality? Am J Clin Nutr 2008, 87:1107-1117.

35. Mishra GD, McNaughton SA, Bramwell GD, Wadsworth ME: Longitudinal changes in dietary patterns during adult life. Br J Nutr 2006, 96:735-744.

36. Cardoso MA, Hamada GS, de Souza JM, Tsugane S, Tokudome S: Dietary patterns in Japanese migrants to southeastern Brazil and their descendants. J Epidemio/ 1997, 7:198-204.

doi:10.1186/1471-2458-14-654

Cite this article as: Arruda et al:: Socioeconomic and demographic factors are associated with dietary patterns in a cohort of young Brazilian adults. BMC Public Health 2014 14:654.

\section{Submit your next manuscript to BioMed Central and take full advantage of:}

- Convenient online submission

- Thorough peer review

- No space constraints or color figure charges

- Immediate publication on acceptance

- Inclusion in PubMed, CAS, Scopus and Google Scholar

- Research which is freely available for redistribution

Submit your manuscript at www.biomedcentral.com/submit
C) BioMed Central 